\title{
Self-Limiting Growth of GaN at Low Temperatures
}

\author{
C. Ozgit, I. Donmez And N. Biyikli*
}

UNAM - Institute of Materials Science and Nanotechnology, Bilkent University, 06800 Ankara, Turkey

GaN thin films were deposited in a self-limiting fashion at low temperatures. Films were deposited on Si substrates by plasma-enhanced atomic layer deposition using trimethylgallium (TMG) or triethylgallium (TEG) as the group-III, and ammonia $\left(\mathrm{NH}_{3}\right)$ as the group-V precursors. TMG and TEG saturations were observed at 185 and $150{ }^{\circ} \mathrm{C}$, for doses starting from 0.015 and $1 \mathrm{~s}$, respectively. Constant deposition rates of $\approx 0.51$ and $\approx 0.48 \AA$ /cycle were obtained within the temperature ranges of $250-350$ and $150-350{ }^{\circ} \mathrm{C}$ for TMG-and TEG-based plasma-enhanced atomic layer deposition processes. Oxygen contents of the films were high $(\approx 20$ at. $\%)$ as determined by X-ray photoelectron spectroscopy.

PACS: 81.05.Ea, 81.15.Gh, 82.80.Pv

\section{Introduction}

Atomic layer deposition (ALD) is a special type of chemical vapor deposition, in which the substrate surface is exposed to sequential pulses of two or more precursors separated by purging periods [1, 2]. Unless decomposition of the precursor occurs, each pulse leads to surface reactions that terminate after the adsorption of a single monolayer. When compared to other thin film deposition methods, ALD stands out with its self-limiting growth mechanism, which enables the deposition of highly conformal thin films with subnanometer thickness control.

$\mathrm{GaN}$ is a wide band gap semiconductor $(3.4 \mathrm{eV})$, which has a great potential for various electronic and optoelectronic device applications [3]. Growth of GaN thin films by atomic layer epitaxy (ALE) using triethylgallium $\left(\mathrm{Ga}\left(\mathrm{C}_{2} \mathrm{H}_{5}\right)_{3}, T E G\right)$ [4], trimethylgallium $\left(\mathrm{Ga}\left(\mathrm{CH}_{3}\right)_{3}, T M G\right)$ [5], and gallium trichloride $\left(\mathrm{GaCl}_{3}\right)$ [6] has been reported for temperatures above $450^{\circ} \mathrm{C}$. Lower growth temperatures $\left(350-400^{\circ} \mathrm{C}\right)$ were achieved when $\mathrm{GaCl}$ was used as the gallium precursor [7]. Sumakeris et al. [8] reported growth of $\mathrm{GaN}$ films within the temperature range of $150-650^{\circ} \mathrm{C}$ by using a novel reactor design that employs hot filaments to decompose the ammonia. Recently, Kim et al. [9] deposited GaN thin films by thermal ALD using $\mathrm{GaCl}_{3}$ and $\mathrm{NH}_{3}$ as the gallium and nitrogen precursors, respectively. In their study, growth rate saturated at $\approx 2.0 \AA /$ cycle within the temperature range of $500-750^{\circ} \mathrm{C}$.

In this work, we demonstrate the self-limiting growth of $\mathrm{GaN}$ thin films via plasma-enhanced ALD (PEALD) within the temperature range of $150-350^{\circ} \mathrm{C}$ using TMG or TEG as the group-III, and $\mathrm{NH}_{3}$ as the group-V precursors.

\footnotetext{
* corresponding author; e-mail: biyikli@unam.bilkent.edu.tr
}

\section{Experimental details}

Depositions were carried out in a Fiji F200-LL ALD reactor (Cambridge Nanotech) with a base pressure of $\approx 0.25$ Torr, using Ar as the carrier gas. $\mathrm{NH}_{3}$ flow rate and plasma power were $50 \mathrm{sccm}$ and $300 \mathrm{~W}$, respectively. System was purged for $10 \mathrm{~s}$ after each precursor exposure. Prior to depositions, pre-cleaned Si (100) and Si (111) substrates were dipped into dilute HF solution for $\approx 1 \mathrm{~min}$, then rinsed with deionized (DI) water and dried with $\mathrm{N}_{2}$.

Film thicknesses were estimated by using variable angle spectroscopic ellipsometry (VASE, J.A. Woollam). Ellipsometric spectra of the samples that were recorded at three angles of incidence $\left(65^{\circ}, 70^{\circ}, 75^{\circ}\right)$ in the wavelength range of $400-1200 \mathrm{~nm}$, were fitted by using the Cauchy dispersion function. Thermo Scientific K-Alpha spectrometer with a monochromatized $\mathrm{Al} K_{\alpha}$ X-ray source was used for the X-ray photoelectron spectroscopy (XPS) studies.

\section{Results and discussion}

GaN thin films were deposited on Si (100) substrates by PEALD using TMG and ammonia $\left(\mathrm{NH}_{3}\right)$. TMG saturation behavior was studied at $185^{\circ} \mathrm{C}$ with a constant $\mathrm{NH}_{3}$ flow duration of $40 \mathrm{~s}$. TMG doses of 0.015 and $0.03 \mathrm{~s}$ resulted with the same deposition rate $(0.46 \AA /$ cycle), indicating that saturation was already achieved at the minimum available TMG pulse time. This is due to the very high vapor pressure of TMG at room temperature. The excessive usage of TMG might be avoided by lowering the temperature of TMG until a decrease in deposition rate is observed.

Figure 1 is the $\mathrm{NH}_{3}$ saturation curve at $185^{\circ} \mathrm{C}$. Deposition rate increased with $\mathrm{NH}_{3}$ flow duration until $90 \mathrm{~s}$ and reached saturation at $\approx 0.56 \AA$ /cycle. Inset of Fig. 1 


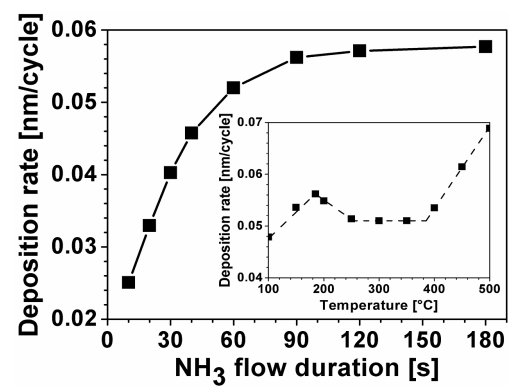

Fig. 1. $\mathrm{NH}_{3}$ saturation curve at $185^{\circ} \mathrm{C}$. TMG dose was constant at $0.015 \mathrm{~s}$. Inset: deposition rate of $\mathrm{GaN}$ as a function of temperature.

shows deposition rates of GaN thin films at different temperatures, where 100 cycles were deposited with $0.015 \mathrm{~s}$ TMG/10 s purge/90 s (50 sccm) $\mathrm{NH}_{3} / 10 \mathrm{~s}$ purge. A constant deposition rate of $\approx 0.51 \AA /$ cycle was observed within the temperature range of $250-350{ }^{\circ} \mathrm{C}$. For temperatures in the range of $185-250^{\circ} \mathrm{C}$, deposition rate increased with decreasing temperature. This behavior is believed to be related to the purging efficiency, which decreases at lower temperatures.

Another set of GaN thin films were deposited on Si (111) substrates by PEALD using TEG and $\mathrm{NH}_{3}$ as the $\mathrm{Ga}$ and $\mathrm{N}$ precursors, respectively. Figure $2 \mathrm{a}$ is the TEG saturation curve at $150^{\circ} \mathrm{C}$. Deposition rate increased with the TEG dose until $1 \mathrm{~s}$. A further increase in TEG dose did not affect the deposition rate, implying that the chemisorption of TEG is self-limiting. Effect of purge time on deposition rate at $150^{\circ} \mathrm{C}$ is given in the inset of Fig. 2a. Deposition rate decreased from 0.60 to $0.49 \AA /$ cycle as the purge time increased from 0 to $5 \mathrm{~s}$, and remained constant at this value for longer purge times. Figure $2 \mathrm{~b}$ shows the $\mathrm{NH}_{3}$ saturation curve at $250^{\circ} \mathrm{C}$. Deposition rate increased with $\mathrm{NH}_{3}$ flow duration until $120 \mathrm{~s}$ and reached saturation at $\approx 0.47 \AA /$ cycle. Deposition rates of $\mathrm{GaN}$ thin films at different temperatures are given in the inset of Fig. 2b. For these experiments, 200 cycles were deposited with $0.5 \mathrm{~s}$ TEG/10 s purge $/ 90 \mathrm{~s}(50 \mathrm{sccm}) \mathrm{NH}_{3} / 10 \mathrm{~s}$ purge. A constant deposition rate of $\approx 0.48 \AA /$ cycle was observed within the temperature range of $150-350^{\circ} \mathrm{C}$. For higher temperatures, deposition rate increased with temperature.

Film thickness vs. number of deposition cycles graphs for $\mathrm{GaN}$ films deposited at $250^{\circ} \mathrm{C}$ using $0.015 \mathrm{~s}$ TMG with $90 \mathrm{~s} \mathrm{NH}_{3}$, and at $150{ }^{\circ} \mathrm{C}$ using $1 \mathrm{~s}$ TEG with $120 \mathrm{~s}$ $\mathrm{NH}_{3}$ are given in Fig. 3. A linear growth behavior was observed for both processes.

Compositional characterizations of the $\approx 16$ and $27 \mathrm{~nm}$ thick GaN films deposited using TMG and TEG precursors, respectively, were carried out by using XPS. Survey scans detected peaks of gallium, nitrogen, oxygen, and carbon. Carbon was detected only at the film surfaces and no $\mathrm{C}$ impurities were found in the bulk films. Oxygen contents of the films deposited using TMG and TEG precursors were 19.5 and 22.5 at.\%, respectively.

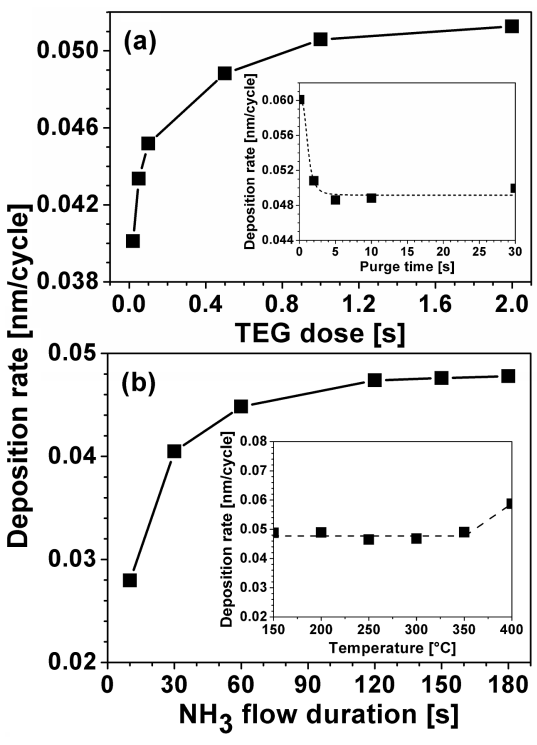

Fig. 2. (a) TEG saturation curve at $150{ }^{\circ} \mathrm{C} \cdot \mathrm{NH}_{3}$ flow duration was constant at $90 \mathrm{~s}$. Inset: deposition rate as a function of purge time. (b) $\mathrm{NH}_{3}$ saturation curve at $250{ }^{\circ} \mathrm{C}$. TEG dose was constant at $0.5 \mathrm{~s}$. Inset: deposition rate of $\mathrm{GaN}$ as a function of temperature.

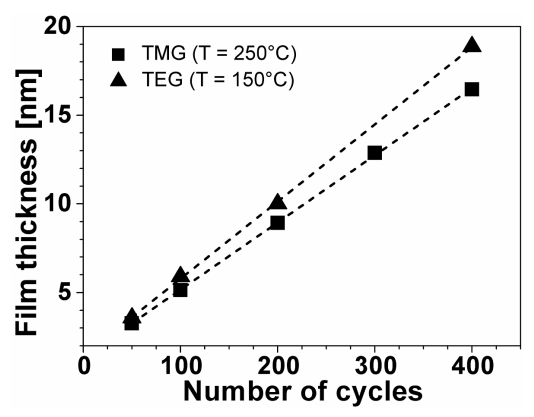

Fig. 3. Film thickness vs. number of deposition cycles.

Ga $3 d$ and N $1 s$ high resolution XPS scans given in Fig. 4 refer to bulk films. In Fig. $4 \mathrm{a}$, Ga $3 d$ scan of the film deposited using TMG was fitted by two peaks located at 19.72 and $20.85 \mathrm{eV}$, which correspond to $\mathrm{Ga}-\mathrm{N}$ $[10,11]$ and $\mathrm{Ga}-\mathrm{O}[10]$ bonds, respectively. Similarly, two subpeaks located at 19.8 and $21.09 \mathrm{eV}$ were assigned as $\mathrm{Ga}-\mathrm{N}[10,11]$ and $\mathrm{Ga}-\mathrm{O}[10]$ bonds, respectively, for the film deposited using TEG as the group-III precursor. In both cases, the intensity of $\mathrm{Ga}-\mathrm{O}$ subpeak was higher than that of the Ga-N subpeak. N $1 s$ scans of the films are given in Fig. 4b. Subpeaks located at 395.07 (TMG) and $395.35 \mathrm{eV}$ (TEG) were assigned as the $\mathrm{N}-\mathrm{O}$ bond $[12,13]$, whereas the ones located at 397.54 (TMG) and $398.03 \mathrm{eV}$ (TEG) were assigned as the N-Ga [14, 15]. Both Ga $3 d$ and $\mathrm{N} 1 s$ scans were shifted to higher energies when TEG was used as the group-III precursor. 


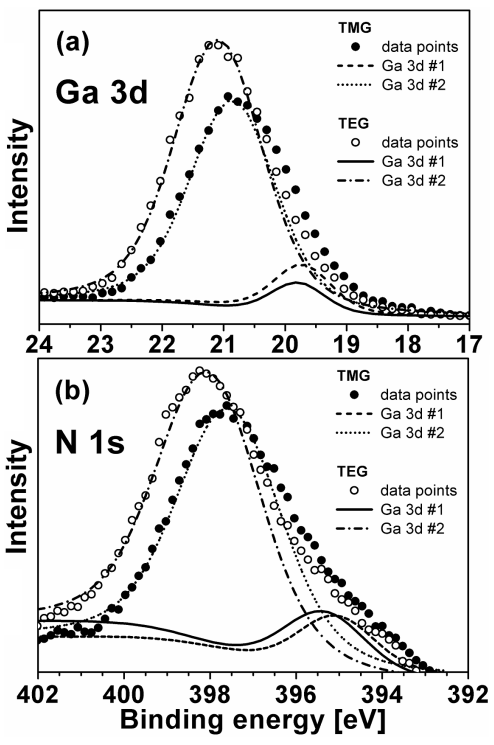

Fig. 4. (a) Ga 3d, and (b) N $1 s$ high resolution XPS scans of GaN thin films.

\section{Conclusions}

GaN thin films were deposited by PEALD at low temperatures. Saturation doses of group-III and $-\mathrm{V}$ precursors were determined as $\left(0.015 \mathrm{~s}\right.$ TMG, $\left.90 \mathrm{~s} \mathrm{NH}_{3}\right)$ and $(1 \mathrm{~s}$ TEG, $120 \mathrm{~s} \mathrm{NH}_{3}$ ). Deposition rates remained constant at $\approx 0.51$ and $\approx 0.48 \AA$ /cycle within the temperature ranges of $250-350$ and $150-350{ }^{\circ} \mathrm{C}$ for TMG- and TEG-based processes, respectively. Both processes exhibited linear growth behaviors. Oxygen contents of the films deposited using TMG and TEG precursors were 19.5 and 22.5 at.\%, respectively.

\section{Acknowledgments}

This work was performed at UNAM supported by the State Planning Organization (DPT) of Turkey through the National Nanotechnology Research Center Project. N.B. acknowledges support from Marie Curie International Re-integration grant (grant \# PIRG05-GA-2009-249196).

\section{References}

[1] M. Leskela, M. Ritala, Thin Solid Films 409, 138 (2002).

[2] R.L. Puurunen, J. Appl. Phys. 97, 121301 (2005).

[3] S.C. Jain, M. Willander, J. Narayan, R. Van Overstraeten, J. Appl. Phys. 87, 965 (2000).

[4] M.A. Khan, R.A. Skogman, J.M. Van Hove, D.T. Olson, J.N. Kuznia, Appl. Phys. Lett. 60, 1366 (1992).

[5] N.H. Karam, T. Parodos, P. Colter, D. McNulty, W. Rowland, J. Schetzina, N. El-Masry, S.M. Bedair, Appl. Phys. Lett. 67, 94 (1995).

[6] H. Tsuchiya, M. Akamatsu, M. Ishida, F. Hasegawa, Jpn. J. Appl. Phys. 35, L748 (1996).

[7] A. Koukitu, Y. Kumagai, T. Taki, H. Seki, Jpn. J. Appl. Phys. 38, 4980 (1999).

[8] J. Sumakeris, Z. Sitar, K.S. Ailey-Trent, K.L. More, R.F. Davis, Thin Solid Films 225, 244 (1993).

[9] O.H. Kim, D. Kim, T. Anderson, J. Vac. Sci. Technol. A 27, 923 (2009).

[10] V. Matolin, S. Fabik, J. Glosik, L. Bideux, Y. Ould-Metidji, B. Gruzza, Vacuum 76, 471 (2004).

[11] P. Kumar, M. Kumar, Govind, B.R. Mehta, S.M. Shivaprasad, Appl. Surf. Sci. 256, 517 (2009).

[12] D. Manova, V. Dimitrova, W. Fukarek, D. Karpuzov, Surf. Coat. Tech. 106, 205 (1998).

[13] C.C. Wang, M.C. Chiu, M.H. Shiao, F.S. Shieu, J. Electrochem. Soc. 151, F252 (2004).

[14] Z. Majlinger, A. Bozanic, M. Petravic, K.-J. Kim, B. Kim, Y.-W. Yang, Vacuum 84, 41 (2010).

[15] M. Drygas, R.T. Paine, J.F. Janik, Pol. J. Chem. Technol. 8, 60 (2006). 